\title{
IMPOLIDEZ E IDENTIDADES EM UMA INTERAÇÃO ON-LINE NO FACEBOOK: UMA ABORDAGEM SOCIODISCURSIVA
}

\author{
IMPOLITENESS AND IDENTITIES IN AN DESCORTESÍA E IDENTIDADES EN UNA \\ ONLINE INTERACTION ON FACEBOOK: INTERACCIÓN EN LÍNEA EN FACEBOOK: \\ A SOCIODISCURSIVE APPROACH UN ABORDAJE SOCIODISCURSIVO
}

\author{
Ricardo Rios Barreto Filho* \\ Universidade Federal de Pernambuco, Centro de Artes e Comunicação, \\ Departamento de Letras, Recife, PE, Brasil \\ Kazue Saito Monteiro de Barros** \\ Universidade Federal de Pernambuco, Centro de Artes e Comunicação, \\ Departamento de Letras, Recife, PE, Brasil
}

\begin{abstract}
Resumo: Os sites de redes sociais, como o Facebook, podem servir como um palco de disputas políticas e ideológicas onde interlocutores entram em conflito, gerando linguagem ofensiva e disputas identitárias. Este artigo objetiva apresentar contribuições que os estudos das identidades podem fornecer à análise da impolidez - uso da língua para causar ofensa - em interações on-line. Para tanto, propõe a análise qualitativa de cunho interpretativista de uma postagem e seus respectivos comentários, coletados no Facebook. Os resultados sugerem que o estudo combinado entre impolidez e identidades possibilita demonstrar que o processo de ofensa nessa plataforma on-line é normalmente inferencial, e depende de processos de identificação com a impolidez presentes nos textos.
\end{abstract}

Palavras-chave: Interação online. Impolidez. Identidade.

\begin{abstract}
The social networking websites, such as the Facebook, have become a place for political and ideological conflicts between the interlocutors, generating offensive language and identity disputes. This paper aims to present the contributions that the identity studies can provide to the impoliteness analysis (the use of language to cause offense) in online interactions. For this purpose, it proposes a qualitative and interpretative analysis of a Facebook post and its respective comments. The results suggest that the combined study between the impoliteness and identities is capable of showing that the offense processes in this online platform are normally inferential and rely on identification processes with the impoliteness in the texts.
\end{abstract}

Keywords: Online interaction. Impoliteness. Identity.

Resumen: Las portadas de redes sociales, como Facebook, pueden servir de escenario de disputas políticas e ideológicas donde interlocutores entran en conflicto, generando lenguaje ofensivo y disputas identitarias. Así, ese artículo tiene el objetivo de presentar contribuciones que estudios de las identidades pueden proveer

* Doutor em Letras (concentração em Linguística) pela UFPE. Professor Adjunto do Departamento de Letras da Universidade Federal de Pernambuco. ORCID: https://orcid.org/0000-0002-2895-2981. Email: ricardo.rios@ufpe.br.

** Doutora em Language and Linguistics pela University of Essex (UK). Professora Titular do Departamento de Letras da Universidade Federal de Pernambuco. ORCID: https://orcid.org/0000-0001-90246239. E-mail: kazuesaito@uol.com.br. 
para análisis de la descortesía - uso de la lengua para causar ofensa - en interacciones en línea. Para ello, propone el análisis cualitativo de naturaleza interpretativa de un postaje y sus respectivos comentarios, colectados en Facebook. Los resultados sugieren que el estudio combinado entre descortesía e identidades haz posible demostrar que el proceso de ofensa en esa plataforma en línea es normalmente de inferencia, y depende de procesos de identificación con la descortesía presentes en los textos.

Palabras clave: Interacción en línea. Descortesía. Identidad.

\section{INTRODUÇÃO}

As redes sociais têm se tornado verdadeiros palcos de debates político-ideológicos, marcados principalmente por um discurso de combate, muitas vezes permeado por uma linguagem conflituosa e, por vezes, rude ou grosseira. Essa realidade no ambiente on-line nos faz questionar sobre o funcionamento interacional dessas disputas, sobretudo em relação a como se dá o processo de ofensa nessas interações.

O campo dos estudos da linguagem a que recorremos para empreender uma investigação sobre essa linguagem conflituosa na internet são os estudos da impolidez ${ }^{1}$. Esses estudos são posteriores e inter-relacionados aos estudos da polidez, que se dedica grosso modo à investigação do uso da língua para gerar interações harmoniosas entre falantes. Os estudos da impolidez, por sua vez, preocupam-se com as interações conflituosas, muitas vezes marcadas por rudeza e agressão.

Embora haja ligação inquestionável entre os estudos da impolidez e da polidez, os estudiosos de impolidez assumem que ela não equivale à ausência de polidez. Para eles, na verdade, uma não é o oposto da outra, pois existem dois fenômenos diferentes que apresentam características linguístico-discursivas e funções sociais particulares.

Como nos interessamos pela linguagem nas interações sociais, perguntamo-nos: como se configura a impolidez em debates on-line no Facebook? Ademais, como a impolidez se inicia e se desenvolve no Facebook e como ela está relacionada a processos de construção de identidades na interação?

Em vista desse questionamento, assumimos aqui uma abordagem sociodiscursiva ${ }^{2}$ dos estudos da impolidez (por exemplo, Eelen (2001), Culpeper (2011) e Culpeper e Hardaker (2017), a qual pretende explicar quais aspectos linguístico-discursivos atuam no processo de ofensa, por meio da análise situada de contextos. Em função de nosso ponto de vista epistemológico, acreditamos que a impolidez emerge da interação e depende não apenas do uso de elementos linguísticos isolados, mas principalmente da associação destes elementos ao contexto, tanto situacional e imediato quanto sóciohistórico.

Além do caráter interacional, a que nossa abordagem se associa, este artigo tem particular interesse em demonstrar o papel dos estudos sobre identidades nas análises da impolidez em ambiente on-line. Para essa discussão, nos apoiamos nos estudos sobre

\footnotetext{
${ }^{1}$ A palavra impolidez é um termo técnico que designa uma linguagem considerada ofensiva.

2 Aqui, optamos por trabalhar apenas com a perspectiva sociodiscursiva de estudos da impolidez. Para detalhamento sobre outras perspectivas, conferir o ensaio de Barros (2017).
} 
identidades de base sociocultural (BUCHOLTZ; HALL 2004a, 2004b 2005) e nas discussões acerca das relações entre impolidez e identidades (BLITVICH; SIFIANOU, 2017). Estas autoras ressaltam que os estudos da impolidez e das identidades têm se desenvolvido tradicionalmente de maneira autônoma sem que haja grande investimento nas inter-relações desses contextos. $\mathrm{O}$ artigo tematiza, portanto, o papel da impolidez no processo de construção das identidades dos interactantes no discurso on-line.

Após esta breve contextualização, explicitamos o conceito de impolidez adotado no trabalho e discutimos as fórmulas de impolidez propostas por Culpeper (2011), que guiarão as análises. A partir da perspectiva sociocultural de Bucholtz e Hall (2004a, 2004b, 2005), explicitamos a noção de identidades e seus princípios, por meio dos quais propomos a abordagem da impolidez para construção das identidades em interações no Facebook. Finalmente, investimos na análise de um post publicado no Facebook, e seus respectivos comentários e réplicas, que servirão de base para a discussão final sobre as relações entre fenômenos de construção de identidade e impolidez.

\section{DEFINIÇÃO E ABORDAGEM DA IMPOLIDEZ NUMA PERSPECTIVA SOCIOINTERACIONAL}

Antes de surgir o interesse pela impolidez, a Linguística dedicou-se à polidez. $\mathrm{O}$ tema foi especialmente explorado por Brown e Levinson (1987), cuja perspectiva teórica investiga as escolhas linguísticas associadas à preservação das faces e das interações harmoniosas ${ }^{3}$.

Especificamente sobre a impolidez, Culpeper e Hardaker (2017 p. 200) explicam que "todas as noções de impolidez parecem envolver comportamentos que são considerados negativos por pelo menos um dos participantes [da interação]" ". Levando em consideração essa definição, partimos do princípio de que a impolidez não é construída pura e simplesmente por escolhas lexicais e construções sintático-semânticas que tradicionalmente são vistas como impolidas. Em outras palavras, não é o simples uso de palavras de baixo calão ou de maldizeres tradicionais que é considerado ofensivo, violento ou impolido, mas as percepções que os interactantes têm dos termos ou expressões.

Neste texto, assumimos que a impolidez é gerada pelo uso da linguagem, cujos sentidos são atualizados no fluxo da interação. Com isso, ratificamos a necessidade de entender a linguagem como uma atividade social orientada pela interação social. É apenas por meio da análise do contexto de interação que podemos sustentar se há ou não impolidez.

${ }^{3}$ O trabalho de Brown e Levinson (1987), além de ter inspirado muitas investigações no campo da Linguística e área afins, também estimulou diversas críticas que deram início a outras perspectivas teóricas e de análise. Neste artigo, no entanto, não temos como intenção revisar de forma aprofundada os estudos da polidez. Contudo, recomendamos Eelen, (2001), Barros (2017) e Culpeper, Haugh e Kádár (2017) para conferir a história dos estudos da polidez, que, sem dúvida, impactam as pesquisas sobre impolidez, como a deste trabalho.

${ }^{4}$ All notions of impoliteness seem to involve behaviours that are considered emotionally negative by at least one participant. 
Dessa maneira, defendemos a noção de que a impolidez é, na verdade, um processo avaliativo dos participantes das interações, que, por sua vez, julgam intersubjetivamente seu discurso bem como o discurso do outro.

Sobre esse assunto, Eelen (2001, p. 109) comenta:

\begin{abstract}
Diariamente, a (im)polidez ocorre nem tanto quando o falante produz o comportamento, mas quando o ouvinte avalia o comportamento [...] a essência da (im)polidez está nesse momento avaliativo. Mesmo que haja ouvintes avaliando falantes, falantes avaliando a si próprios, ou informantes avaliando falantes hipotéticos ou enunciados, esse momento avaliativo sempre estará presente. De fato, na prática este parece ser o único jeito que a (im)polidez possa ser estudada. A avaliação é, portanto, a maneira primordial de ser da (im)polidez. ${ }^{5}$
\end{abstract}

A visão do autor demonstra a natureza contextual da (im)polidez ${ }^{6}$, uma vez que ela se estabelece pela avaliação que interactantes fazem dos comportamentos (verbais ou não) face ao contexto situacional e também ao contexto social mais amplo. Por essa razão, não acreditamos ser possível determinar a priori um conjunto de expressões naturalmente impolidas. Alguns itens lexicais podem ganhar valor impolido em alguns grupos sociais ao passo que em outros esse valor é perdido. Os xingamentos e palavrões podem ser avaliados, por exemplo, como um indício de intimidade na interação entre amigos, ao passo que podem ser vistos como grosseiros na relação entre desconhecidos. O que poderá nos fazer perceber a impolidez é, na verdade, a análise de contextos situados de interação.

Sobre a questão do contexto, cabe ressaltar que ele não é preestabelecido, mas depende da co-construção que os interactantes fazem no fluxo interacional, na maioria das vezes de maneira imperceptível e não notada pelos falantes. No caso de uma briga ou discussão, é incomum que os interactantes anunciem verbalmente que estão iniciando uma. No entanto, há certos elementos verbais e não verbais que indicam implicitamente a formação dessas situações.

Acerca dessa construção interacional do contexto, Gumperz (1982) chama a atenção para o conceito de pistas de contextualização, que é definido como "qualquer característica da forma linguística que contribui para sinalizar o contexto pressuposto"7 (GUMPERZ, 1982, p. 131). Portanto, ao assumir que a impolidez depende da avaliação do contexto de uso da língua pelos interlocutores, partimos do princípio de que, para identificar situações de impolidez, é preciso analisar o discurso a partir das reações visíveis dos interactantes.

${ }^{5}$ In everyday practice (im)politeness occurs not so much when the speaker produces behaviour but rather when the hearer evaluates that behavior [...] the very essence of (im)politeness lies in this evaluative moment. Whether it involves hearers evaluating speakers, speakers evaluating themselves, or informants evaluating hypothetical speakers or utterances, the evaluative moment is always present. Indeed, in practice it proves to be the only way in which (im)politeness can be studied. Evaluation is thus the basic, primordial mode of being of (im)politeness.

${ }^{6} \mathrm{Na}$ literatura especializada, o termo (im)polidez, com o prefixo entre parênteses, é usado para designar tanto a polidez - uso marcado da linguagem para criar harmonia na interação - quanto a impolidez uso da linguagem para gerar ofensa. É ainda importante ressaltar que o termo (im)polidez carrega uma ideia de conceito guarda-chuva, que designa diversas avaliações rotuladas como bem-educadas, corteses, rudes, grosseiras, mal-educadas etc.

${ }^{7}$ A contextualization cue is any feature of linguistic form that contributes to the signaling of contextual presuppositions. 
Em outras palavras, para identificar um insulto - e possivelmente diferenciá-lo de uma brincadeira - é preciso que o analista invista na interpretação das pistas de contextualização relacionadas à impolidez que possam ser associadas a emoções negativas. A análise da impolidez passa, portanto, pela análise de pelo menos três aspectos que Culpeper e Hardaker (2017) enumeram: texto, co-texto e contexto.

Em relação ao texto, destacamos as escolhas lexicais e construções sintáticosemânticas dos discursos, que devem ser analisadas em relação à porção maior de texto que as circundam, ou seja, o co-texto. Aliado a esses dois aspectos, também deve-se analisar o próprio contexto imediato de interação, percebido por meio das pistas de contextualização (GUMPERZ, 1982), que revelam sentidos implícitos e pressupostos não presentes na superfície do texto e co-texto. Também fazem parte do contexto aspectos relacionados ao horizonte social mais amplo, os quais estão associados às relações de poder, ideologias e identidades.

Assim, a perspectiva que nossa análise empreende ao estudo da impolidez alinhase à perspectiva interacionista de autores como Bakhtin/Volochínov ${ }^{8}$, ao defender que:

\begin{abstract}
Qualquer que seja o aspecto da expressão-enunciação considerado, ele será determinado pelas condições reais da enunciação em questão, isto é, antes de tudo pela situação social mais imediata. [...] Na maior parte dos casos, é preciso supor além disso um certo horizonte social definido e estabelecido que determina a criação ideológica do grupo social e da época a que pertencemos, um horizonte contemporâneo da nossa literatura, da nossa ciência, da nossa moral, do nosso direito. (grifos do autor). (BAKHTIN/VOLOCHÍNOV, 2006, p 116)
\end{abstract}

Em resumo, assumimos como interações impolidas aquelas nas quais pelo menos um dos participantes demonstra avaliações de comportamentos (verbais ou não) associados a emoções negativas (CULPEPER et al., 2014; CULPEPER; HARDAKER, 2017). Ademais, chegamos também à conclusão de que o estudo da impolidez se dá a partir da análise da linguagem em contexto situado, ou seja, por meio da consideração da materialidade do texto e do co-texto, associado ao estudo do contexto, que inclui tanto o contexto situacional imediato, quanto o horizonte social mais amplo.

A partir desses pressupostos, reconhecemos a necessidade de utilizar categorias linguístico-discursivas que auxiliem a análise da impolidez. Embora não seja possível, como já dissemos, determinar categorias infalíveis de análise da impolidez, é possível conceber construções sintático-semânticas e escolhas lexicais normalmente associadas à impolidez, em função da sua regularidade em interações impolidas.

Sobre essas categorias, Culpeper (2011) apresenta as fórmulas convencionalizadas de impolidez, ou seja, fórmulas linguístico-discursivas normalmente associadas a situações de impolidez. O pesquisador chegou a elas por meio de uma pesquisa extensiva de corpora de interações impolidas em inglês britânico, tais como treinamentos militares, programas "de baixaria", documentários violentos, pichações, relatos de situações de impolidez e outros gêneros de texto em que a impolidez é esperada ${ }^{9}$.

\footnotetext{
${ }^{8}$ Em função da indefinição sobre a autoria dessa obra, preferimos exibir o nome dos dois autores, embora reconheçamos que apenas um deles de fato a escreveu.

${ }^{9}$ Para Culpeper (2011), é difícil a coleta de situações espontâneas em que a impolidez aparece por questões éticas. Por isso, seu principal campo de coleta de dados de impolidez são textos públicos onde a ofensa já é esperada, como em alguns programas de TV que exploram brigas e insultos entre participantes.
} 
As fórmulas convencionalizadas de impolidez são diferentes de categorias linguístico-discursivas preconcebidas na teoria para serem aplicadas posteriormente à prática, pois, na verdade, elas foram concebidas a partir de uma análise extensiva de dados. Além disso, o autor esclarece que, embora as fórmulas sejam indicativo de impolidez, elas não são infalíveis, pois, conforme estivemos defendendo, a impolidez depende do contexto e deve ser analisada a partir dele. Outra ressalva sobre as fórmulas é que elas foram concebidas a partir da análise de corpora em uma língua específica, o inglês britânico. Culpeper e Hardaker (2017) ressaltam que elas não foram empiricamente comprovadas em dados de outras culturas e línguas.

Em nosso caso, julgamos que as fórmulas são indícios de impolidez que podem nos fornecer capacidade analítica, uma vez que são definidas e conceituadas a partir da análise de interações reais, mesmo que em outra cultura. Ademais, seguimos as indicações dos autores, que explicam que a simples identificação de fórmulas convencionalizadas de impolidez é apenas uma etapa inicial do exercício de análise, pois as conclusões e resultados de análise só tomam forma a partir da associação da linguagem a aspectos contextuais das interações. Por essas razões, percebemos que as fórmulas, embora elaboradas com base em uma única língua, atendem a nossos objetivos de análise se considerarmos as devidas adaptações para o contexto cultural analisado.

Apresentamos, no Quadro 1 a seguir, as fórmulas convencionais de impolidez de Culpeper (2011), com a devida tradução dos exemplos para nosso contexto de pesquisa em língua portuguesa.

\begin{tabular}{l|l} 
Fórmulas Convencionalizadas de Impolidez & Exemplos \\
\hline Insultos (vocativos negativos personalizados) & Seu idiota \\
\hline Insultos (afirmações negativas personalizadas) & Você é uma puta \\
\hline Insultos (referências negativas personalizadas) & No seu cu \\
\hline $\begin{array}{l}\text { Insulto (referência negativa a outra pessoa na presença } \\
\text { do alvo) }\end{array}$ & Aquela tapada \\
\hline Crítica/reclamação acentuada & Isso tá uma merda \\
\hline Desafio, perguntas ou pressuposições desagradáveis & Por que você faz a minha vida impossível? \\
\hline Arrogância & Você está sendo infantil \\
\hline Reforços de mensagens & Escuta aqui! \\
\hline Dispensas & Vai se foder (no sentido de sai daqui) \\
\hline Silenciadores & Cala tua boca \\
\hline Ameaças & Eu vou dar um tiro na porra da tua cabeça se tocar no \\
\hline Maldições e maldizeres & meu carro \\
\hline
\end{tabular}

\section{Quadro 1 - Fórmulas convencionalizadas da impolidez}

Fonte: Retirado e traduzido de Culpeper (2011, p. 135-136). 
Conforme chamam a atenção Blitvitch e Sifianou (2017), os estudos da (im)polidez e das identidades tradicionalmente tomaram caminhos separados. Embora esses dois fenômenos tenham sido alvo de estudos interacionais, eles parecem ter se desenvolvido sem que tivesse sido tematizada a relação e influência mútua entre esses dois temas.

Levando em consideração a discussão iniciada pelas autoras, objetivamos, neste trabalho, discutir como o estudo combinado sobre a construção interacional das identidades é relacionado ao fenômeno da impolidez e vice-versa. Para tanto, utilizamos um aparato teórico que parte do princípio da interação social. Uma vez definida a noção de impolidez (seção 2), passamos a demonstrar como as identidades podem ser estudadas a partir da perspectiva interacionista.

Vemos as identidades como o "posicionamento social do eu e do outro" (BUCHOLTZ; HALL, 2005, p. 586). Assim, assumimos que há diferentes posicionamentos sociais ou agrupamentos, e que as pessoas se identificam com determinados grupos, mas não com outros. No que tange ao uso da linguagem, pressupomos que ela varia, e um dos fatores que influenciam essa variação é justamente o posicionamento social nesses agrupamentos, ou seja, as identidades.

A maneira como nos identificamos face aos agrupamentos sociais faz com que escolhamos determinados estilos linguísticos ou mesmo tenhamos interpretações semelhantes (ou diferentes) de fenômenos sociais, como é o caso da própria impolidez. Talvez um determinado comportamento ou insulto só seja visto de forma ofensiva se nos identificarmos de alguma maneira com o grupo ou identidades insultadas.

Reconhecendo a importância que as identidades têm para a vida social, podemos nos perguntar como elas são construídas e como são percebidas pelas pessoas. Pressupomos que sejam construídas e percebidas também pela interação social.

Assumindo o conceito de identidades como emergindo da interação, Bucholtz e Hall (2004) afastam-se das chamadas abordagens essencialistas da questão, ou seja, que postulam uma essência preestabelecida, normalmente biologicamente determinada. Assim, as estudiosas chamam a atenção para as seguintes críticas:

\footnotetext{
Os críticos têm acusado os pesquisadores das identidades de essencialismo, um posicionamento teórico que sustenta que aqueles que ocupam uma categoria identitária (como mulher, asiático, classe trabalhadora) são fundamentalmente similares entre si e fundamentalmente diferentes de membros de outros grupos. O essencialismo pressupõe que esses agrupamentos são inevitáveis e naturais, e que há limites contundentes que separam um grupo de outro. ${ }^{10}$ (BUCHOLTZ; HALL, 2004, p. 374)
}

\footnotetext{
${ }^{10}$ Critics have charged researchers of identity with essentialism, a theoretical position that maintains that those who occupy an identity category (such as women, Asians, the working class) are both fundamentally similar to one another and fundamentally different from members of other groups. Essentialism takes as its starting point that these groupings are inevitable and natural, and that they are separated from one another by sharp boundaries.
} 
A abordagem essencialista das identidades é problemática do ponto de vista interacional, pois assumir esse ponto de vista seria aceitar que há fatores já preestabelecidos, imutáveis e anteriores à interação, a ponto de predizer exatamente de qual estilo determinado interactante faria uso, tomando com base informações demográficas. Outra concessão à realidade que teríamos de fazer é que assumiríamos que todos os membros de um dado grupo agiriam da mesma forma, teriam o mesmo estilo de linguagem, interpretariam insultos da mesma maneira. Em verdade, sabemos que dentro de uma mesma identidade há posicionamentos internos diferentes, os quais ocasionam, consequentemente, diferenças no uso da linguagem.

Além disso, as pessoas não estão identificadas em um único agrupamento social. Pelo contrário, a vida social exige a ocupação de posições sociais sobrepostas. Nunca falamos de uma identidade única; os interactantes, na verdade, assumem diversas posições sociais que dizem respeito a suas vidas públicas, íntimas, profissionais, acadêmicas, regionais etc. Dessa forma, adotar uma postura essencialista parece-nos simplório, o que não dá conta da diversidade de papéis que podemos assumir ao longo da interação social.

Por essa razão, corroboramos a visão de Bucholtz e Hall (2004, 2005), para quem as identidades são construídas nas interações:

\begin{abstract}
Nós defendemos o valor analítico de abordar a identidade como um fenômeno relacional e sociocultural que emerge e circula em contextos discursivos locais de interação em vez de uma estrutura estável localizada na psique individual ou em categorias sociais fixas. ${ }^{11}$ (BUCHOLTZ; HALL, 2004, p. 585-586).
\end{abstract}

Ao ratificar a natureza relacional e sociocultural, as autoras ressaltam que as identidades emergem da necessidade de relacionar-se com o outro, em um determinado agrupamento social, como nacionalidade, gênero, etnia, orientação sexual entre outros. As identidades surgem da necessidade de diferenciar um grupo de outro, ou seja, pela relação entre os grupos sociais. Elas também são socioculturais, pois nascem das interações locais e são sustentadas por interações anteriores, uma vez que a cultura é produzida quando os interactantes se baseiam em múltiplas vozes, textos e diferentes enunciados (BAKHTIN, 1981).

Levando em conta essas características das identidades, Bucholtz e Hall (2005) apresentam categorias analíticas que permitem a abordagem interacional das identidades, com base em cinco princípios: emergência, posicionalidade, indexicalidade, relacionalidade e parcialidade. O princípio da emergência indica que as identidades emergem e são construídas pela linguagem nas interações, e se contrapõe à noção de identidades como categorias sociais fixas ou contidas na psique individual dos seres humanos. O princípio da posicionalidade aborda a heterogeneidade dos grupos identitários; dessa maneira, defende-se que, quanto à noção de identidades, há espaço para categorias identitárias locais e posicionamentos interacionais transitórios, os quais

\footnotetext{
${ }^{11}$ We argue for the analytic value of approaching identity as a relational and sociocultural phenomenon that emerges and circulates in local discourse contexts of interaction rather than as a stable structure located primarily in the individual psyche or in fixed social categories.
} 
emergem de necessidades interacionais imediatas. O princípio da indexicalidade diz respeito à maneira como as identidades são construídas linguisticamente por meio de índices identitários, ou seja, elementos linguístico-discursivos que fazem referência a uma identidade e possibilitam sua identificação no discurso. O princípio da relacionalidade explica que as identidades se constituem a partir de uma relação de alteridade, ou seja, pela diferença ou semelhança com as outras. Por fim, o princípio da parcialidade ratifica que nenhuma construção identitária é capaz de expressar o todo da identidade: todas as construções são apreensões parciais e limitadas de um agrupamento social.

Neste trabalho nos concentramos em dois princípios: indexalidade e relacionalidade, uma vez que são cruciais para a investigação em pauta. Usamos o princípio da indexalidade porque estamos interessados em identificar como a impolidez pode funcionar como um índice identitário, visto que as fórmulas de impolidez podem estar relacionadas ideologicamente a grupos sociais. Ademais, nos interessamos em discutir como a relação entre as identidades também é construída pela impolidez, na medida em que esta cria relações de afastamento ou distanciamento entre identidades construídas na interação.

Ainda sobre a relacionalidade, devemos comentar sobre seu funcionamento a partir de categorias de análise nomeadas de táticas de intersubjetividade (BUCHOLTZ; HALL, 2004a, 2004b, 2005). Essas táticas são maneiras de uma identidade se relacionar a outra. As autoras explicam que são criadas relações de semelhança e diferença entre identidades, mas elas sustentam que há processos mais complexos que vão além desse eixo (semelhança versus diferença).

Bucholtz e Hall (2005) apontam pelo menos três eixos, que são divididos por uma razão didática, mas podem funcionar em conjunto: adequação e distinção, autenticação e desnaturalização, autorização e deslegitimação.

Adequação e distinção dizem respeito às semelhanças e diferenças entre as identidades. De um lado, a adequação ocorre quando as características das identidades são enfatizadas, enquanto as diferenças são postas em segundo plano. Por outro lado, a distinção decorre da ênfase às diferenças entre identidades.

Autenticação e desnaturalização, por sua vez, "são processos pelos quais os falantes reivindicam a autenticidade ou artificialidade respectivamente ${ }^{12 ،}$ (BUCHOLTZ; HALL, 2005, p. 602). Quando se questiona a autenticidade de um membro a dado grupo identitário, que, de acordo com as expectativas ideológicas, pertenceria a ele, há uma tática de desnaturalização. Por outro, o movimento oposto seria a tática de naturalização.

Autorização e deslegitimação se referem à afirmação ou à censura de uma identidade em relação ao poder ideológico e institucionalizado, seja este local ou translocal. Em outras palavras, a autorização confere poder a uma identidade, ao passo que a deslegitimação censura o poder de grupos identitários.

Por meio desse quadro, as autoras ratificam o dinamismo das identidades e esclarecem:

$12[\ldots]$ are the processes by which speakers make claims to realness and artifice, respectively. 
[n]osso objetivo é desenvolver um quadro mais completo da identidade que não a represente como um fenômeno monolítico e estático ou algo que seja inerentemente distintivo ou determinístico nos seus reflexos linguísticos. Esse processo produz um complexo de relações intersubjetivas que se combinam e recombinam de maneira imprevisível e contextualmente situadas. As táticas de intersubjetividade que caracterizamos anteriormente certamente não são os únicos tipos de relações identitárias que emergem na linguagem, e uma questão para pesquisas futuras seria que outras relações podem ser construídas entre posições subjetivas. ${ }^{13}$

(BUCHOLTZ; HALL, 2004b, p. 506).

O aparato de análise proposto pelas pesquisadoras serve a nosso estudo como proposta de trabalho interacional para abordar a questão das identidades. A seguir, propomos a análise de uma interação on-line, no Facebook, que demonstra como a impolidez influencia a construção das identidades e vice-versa.

\section{IMPOLIDEZ E IDENTIDADES NO FACEBOOK}

Os dados foram originalmente utilizados no projeto de pesquisa "Avaliações da (Im)polidez em interações no Facebook" (BARRETO FILHO, 2019). Todos os textos coletados pelo projeto são públicos, mas decidimos retirar todas as referências pessoais que possam identificar os participantes das interações, por questões éticas. Em função disso, os textos estão transcritos com os seguintes codinomes: autor(a) do post para quem fez a postagem e comentador(a) $\mathbf{1}$ e $\mathbf{2}$ para os usuários que fizeram comentários e réplicas na postagem, enumerados de acordo com sua ordem de aparecimento na interação.

O debate se centra na discussão sobre aborto. Nos excertos escolhidos, vemos a postagem que deu origem à discussão e os comentários que foram feitos pela autora do texto e pelos comentadores 1, um homem, e pela comentadora 2, outra mulher. É de nosso conhecimento que a autora do post e o comentador 1 se conhecem off-line, ou seja, fora das redes. A comentadora 2 só conhece e é amiga no Facebook da autora do post, porém o comentador 1 não está em sua lista de amigos ou seguidores.

O Excerto 1 é uma postagem sobre os direitos reprodutivos das mulheres. A autora do post meramente compartilha um texto de outra rede social, o Twitter, em sua página pessoal do Facebook, situação bastante comum neste site de redes sociais. Nesses casos, verificamos em Barreto Filho (2019) que, embora a autoria dos compartilhamentos não seja dos autores do post, os usuários assumem que o compartilhador concorda e se responsabiliza pelas opinões dos textos. Vejamos a publicação sem os respectivos comentários no Excerto 1.

\footnotetext{
${ }^{13}$ Our aim is to develop a more complete picture of identity that does not represent it as a monolithic or static phenomenon or as something that is inherently distinctive or deterministic in its linguistic reflexes. This process yields a complex of intersubjective relations that combine and recombine in unpredictable and contextually situated ways. The tactics of intersubjectivity that we characterize above are certainly not the only sorts of identity relations that merge in language, and one question for future research is what other relationships may be constructed between subject positions.
} 


\title{
Excerto 1: Post
}

Autora do post compartilhou uma postagem

Tweet
se vc acha aborto tão errado, vai
criar
vai arranjar essa mãe desesperada a
condições de cobrar pensão
vai conseguir vaga na creche pra
ela poder trabalhar
agora se vc nao vai fazer nada
disso, cala a boca e nao se mete
no que nao é da sua conta
6.253 Retweets $10,5 \mathrm{~K}$ curtidas

$\mathrm{O}$ post 1 apresenta um tom direto e sem quaisquer marcas linguístico-discursivas que objetivem a polidez. Pelo contrário, o texto inclusive utiliza-se de fórmulas convencionalizadas de impolidez, como o silenciador (CULPEPER, 2011), quando no último parágrafo enuncia "cala a boca e não se mete no que não é da sua conta". É perceptível que o texto apresenta índices que o identificam com a ideologia feminista, uma vez que o tema abordado se pauta pela defesa do direito das mulheres de serem protagonistas nas escolhas relacionadas à reprodução.

Cabe esclarecer aqui que o princípio da indexicalidade de Bucholtz e Hall (2005) explica que os índices de identidade podem ser construídos a partir de vários elementos linguístico-discursivos, além das marcas visíveis no texto.

\begin{abstract}
Diferentes processos indexais de rotulação, de implicatura, de posicionamentos argumentativos, de marcações de estilo e de escolhas de código funcionam para construir identidades, tanto micro quanto macro, bem como as híbridas. Considerar a formação da identidade, em múltiplos níveis indexais, em vez de focar em apenas um, pode nos auxiliar na construção de retrato mais rico da subjetividade e intersubjetividade já que estas são construídas em interação. ${ }^{14}$ (BUCHOLTZ; HALL, 2005, p. 598).
\end{abstract}

Por essas razões, devemos perceber que o posicionamento argumentativo em favor de certas pautas já pode indiciar a identidade feminista. Além disso, considerando o horizonte social (BAKHTIN/VOLOCHÍNOV, 2006) a que o feminismo se associa, reconhecemos que o texto dirige-se a posicionamentos ideológicos contrários, que não partilham da ideia de que à mulher faculta-se o direito de escolher pela interrupção ou não da gravidez. Portanto, o silenciador "cala a boca e não se mete no que não é da sua conta", embora não esteja explicitamente direcionado a um interactante específico, volta-

\footnotetext{
${ }^{14}$ Disparate indexical processes of labeling, implicature, stance taking, style marking, and code choice work to construct identities, both micro and macro, as well as those somewhere in between. By considering identity formation at multiple indexical levels rather than focusing on only one, we can assemble a much richer portrait of subjectivity and intersubjectivity as they are constituted in interaction.
} 
se a identidades discordantes, entre elas, por exemplo, as ideologias religiosas que não aceitam a opinião de que a mulher pode optar pelo aborto.

Vejamos, no excerto 2, como a discussão se desenvolve a partir de comentários e réplicas ao post:

\section{Excerto 2: Comentários e réplicas do post 1}

1 Comentador 1: Autora do post, com esses comentários que você fez eu, de fato,

2 fiquei chateado.

3 Estou por aqui pensando que você quer tirar a sua criança. Por favor, Autora do post,

4 não faça isso.

5 Se você fizer isso, de fato, a mãe de Deus vai ficar preocupada e as coisas não vão

6 caminhar. Continue com a sua criança que tudo dá certo.

7 Saiba. Se você precisar da minha ajuda, estarei aqui pra te ajudar e te amparar.

8 Dinheiro, uma casa pra morar, várias e várias palavras de incentivo e tudo o mais que

9 você quiser.

10 Essa é a verdade, minha amiga. Saiba. A vida é uma glória de Deus e a gente precisa

11 dela pra tudo caminhar. Fica aí um abraço pra você. Muita saúde e a gente se fala.

Autora do post: Não, comentador 1, não quero tirar a minha criança. Mas continuo apoiando as mulheres que querem e precisam. Isso é escolha delas. Mas agradeço a sua proposta de amparo.

Nos comentários que seguem a postagem (linhas 1 a 12), vemos que o comentador 1 responde à autora do post apresentando um posicionamento argumentativo diferente do texto compartilhado, cujos índices de identidade apontam uma identificação religiosa cristã, consequentemente contrária ao aborto. Vários índices são dispostos explicitamente para criar um debate, tanto de ideias quanto de identidades, como a referência a Maria, mãe de Jesus, na linha 5, e a referência a Deus, na linha 10.

O comentador 1, na extensão de seu texto (linhas 1 a 12), parece inferir que a autora do post, que está grávida, pretende abortar, o que é negado na réplica da autora do post, entre as linhas 13 e 15. Percebe-se aí que um assunto que se pautava pelo domínio de um tema público torna-se privado ao adicionar informações da vida íntima da autora do post. Embora não seja o foco da análise, percebe-se que o comentador 1 utiliza-se de uma linguagem polida, principalmente ao final de seu texto ao despedir-se com um abraço e desejos de saúde e de reencontro. Cremos que a polidez é usada aqui em função da delicadeza social do tema: pressupor que uma mulher grávida realizará um aborto.

Chama-nos particular atenção, no entanto, a réplica da comentadora 2, na linha 16, que contém a frase em inglês "No uterus, no opinion". Com o objetivo de calar o comentador 1, a comentadora 2 faz o uso de um silenciador, uma da fórmulas convencionalizadas de impolidez (CULPEPER, 2011) para interromper a fala de alguém. Dessa maneira, percebemos que a comentadora 2 utiliza-se da impolidez, uma vez que 
não responde de maneira harmônica, de modo a expressar sua revolta frente ao fato de que um homem opina sobre os direitos reprodutivos de uma mulher.

O silenciador, nesse caso, age como uma pista de contextualização (GUMPERZ, 1982), que demonstra o sentimento de revolta da comentadora 2. Assim, é possível inferir que, mesmo com o investimento de polidez do comentador 1, a usuária avaliou seu discurso como socialmente inadequado, revoltando-se.

Percebemos que esse enunciado, além do seu sentido imediato para interação, faz menção a outro texto anterior a ele, notadamente uma fala da personagem Rachel Green do seriado norte-americano Friends. Essas mesmas palavras foram usadas pela personagem para tentar silenciar dois homens que tentavam opinar sobre o uso de anestésicos durante o parto natural. Essa observação reverbera de forma mais explícita o fato de que os enunciados são formados e sustentados a partir de enunciados anteriores, os quais constituem a cultura, conforme o pensamento de Bakhtin (1981).

É visível que o silenciador não apenas cumpre seu objetivo imediato na interação, mas também constrói a identidade da comentadora 2. A interlocutora se identifica de alguma forma com o feminismo, pois defende uma pauta da agenda desse grupo identitário. Simultaneamente, ela busca deslegitimar o comentador 1, categorizando-o como um interactante que não tem poder para opinar sobre o assunto em pauta. Percebese, nessa interação, que a impolidez, sustentada pela análise do silenciador em conjunto com o contexto de identidades antagônicas, não funciona apenas como um jogo de ofensas individuais, mas como processo de disputa ideológica em que são atingidos não apenas indivíduos, mas grupos identitários indexados a partir da impolidez. Aqui vemos não apenas uma fórmula convencionalizada de impolidez, mas um silenciador imbuído de sentidos ideológicos que, por sua vez, atinge identidades alheias.

Em pesquisas anteriores (BARRETO FILHO, 2019; BARRETO FILHO; NEVES; BARROS, 2019), verificamos que nas discussões sobre temas públicos no Facebook são comuns esses ataques identitários que provocam reações de usuários que não foram diretamente chamados para a interação. Vemos que a comentadora 2 sentiu-se incomodada com o comentador $1 \mathrm{e}$, com isso, mesmo sem conhecê-lo ou ter sido chamada diretamente à interação, reagiu rispidamente ao comentário. Defendemos, portanto, que a ofensa nesse site de redes sociais é normalmente um processo de "vestir a carapuça", ou seja, identificar-se com a impolidez presente nos discursos.

Muito além de um debate entre pessoas, esse post e seus comentários se caracterizam por um debate entre identidades, nesse caso a feminista e a cristã, que são por sua vez construídas a partir de índices identitários. Particularmente no caso da comentadora 2, a impolidez deflagrada pelo silenciador (No uterus, no opinion!), aplicado a esse contexto em especial, é um índice da identidade feminista. Percebe-se que a impolidez aqui usada se constitui pela necessidade de silenciar a voz de um homem que é deslegitimado, o que nos leva a crer que a comentadora 2 sentiu a necessidade de agir frente ao que ela julga como injustiça, não apenas nessa interação local, mas no contexto translocal entre as identidades de homens e mulheres, já que o silenciador utilizado pela comentadora 2, na linha 16, não se direciona apenas à figura individual do comentador 1 , mas a todos os homens que possam querer emitir opiniões sobre os direitos reprodutivos das mulheres. Portanto, a gênese da impolidez contida na fala da comentadora 2 nasce de um sentimento de revolta e injustiça. 
Este texto parte da provocação iniciada em Blitvitch e Sifianou (2018), que defendem o trabalho conjugado entre a construção das identidades e a impolidez. Em nosso caso, cremos que essa conjunção deve começar por um ponto de partida em comum, a interação social.

Por essa razão, trouxemos neste artigo a perspectiva interacional da impolidez, presente em Eelen (2001), Culpeper (2011) e Culpeper e Hardaker (2017), bem como os estudos da identidade em perspectiva interacional de Bucholtz e Hall (2004a, 2004b e 2005). Ao realizar o estudo de caso de uma interação on-line no Facebook, notamos que o processo de construção das identidades é influenciado pela configuração da impolidez de natureza ideológica.

Nossas conclusões ratificam aquelas de Blitvich e Sifianou (2017) quando defendem que a impolidez pode servir como um índice de construção das identidades. Consequentemente, a impolidez pode representar um caminho para o estudo das construções identitárias na internet, já que, nesse novo espaço de interação, são comuns os debates político-ideológicos acerca de temas de interesse social, normalmente envolvidos por linguagem impolida e ofensiva.

Coadunamos, dessa forma, com as conclusões presentes em trabalhos anteriores (BARRETO FILHO, 2019; BARRETO FILHO; NEVES; BARROS, 2019) que demonstram que a ofensa, na internet, é um processo inferencial de "vestir carapuças", uma vez que, em decorrência da natureza pública das interações no Facebook, os interactantes precisam identificar-se com os discurso proferidos para que se sintam ofendidos, mesmo quando não são chamados à conversa. A pesquisa sobre impolidez na internet pode, dessa maneira, lançar luz sobre as discussões e conflitos em ambientes digitais, de modo a contribuir para explicar hábitos de uso da internet.

Este trabalho encerra-se, portanto, lançando a provocação para trabalhos futuros que investiguem o processo de construção das diversas identidades a partir do discurso impolido, explorando, por exemplo, relações de poder hegemônico e a construção desses discursos em sua relação com as identidades minoritárias. Dessa maneira, talvez possamos melhor compreender o surgimento de polarizações e conflitos verbalmente violentos em sites de redes sociais.

\section{REFERÊNCIAS}

BAKHTIN, M. M./VOLOCHÍNOV, V. Marxismo e filosofia da linguagem. São Paulo: Hucitec, 12 ed. 2006.

BAKHTIN, M. M. The dialogic imagination: four essays. Austin: Univerisity of Texas, 1981. Trad. Caryl Emerson e Michael Holquist.

BARRETO FILHO, R. R. Avaliações da (im)polidez em interações no Facebook. 2019. 268 f. Tese (Doutorado) - Curso de Letras, Departamento de Letras, Universidade Federal de Pernambuco, Recife, 2019.

BARRETO FILHO, R. R.; NEVES, H; BARROS, K S M. Impolidez em textos on-line no facebook: análise das escolhas lexicais numa perspectiva textual-interativa. Calidoscópio, São Leopoldo, v. 17, n. 3, p. 433452, 5 jun. 2019. Disponível em: http://dx.doi.org/10.4013/cld.2019.173.02. Acesso em: 19 ago. 2019. 
BARROS, K S M. Perspectivas nos estudos da polidez. In: CABRAL, A L T; SEARA, I R; GUARANHA, M. F. Descortesia e cortesia: expressão de culturas. São Paulo: Cortez, 2017. p. 359-374. BLITVICH, P; SIFIANOU, M. (Im)politeness and Identity. In: CULPEPER, J; HAUGH, M; KÁDÁR, D. The Palgrave Handbook Of Linguistic (im)politeness, [s.1.]: Palgrave Macmillan UK, 2017. p. 227-256. BROWN, P; LEVINSON, S. Politeness. Cambridge: Cambridge University, 1987.

BUCHOLTZ, M.; HALL, K. Language and Identity In: DURANTI, A. (Ed.) A Companion to Linguistic Anthropology, p. 369-394. Malden, MA: Blackwell, 2004a

BUCHOLTZ, M.; HALL, K. Theorizing Identity in Language and Sexuality Research. Language in Society, [s. 1.], v. 33, n. 4, p. 469-515, set. 2004.

BUCHOLTZ, M.; HALL, K. Identity and interaction: a sociocultural linguistic approach. Discourse Studies, [s.1.], v. 7, n. 4, p. 585-614, 1 out. 2005.

CULPEPER, J. Impoliteness: Using Language to Cause Offence. New York: Cambridge University Press, 2011.

CULPEPER, J. et al. Impoliteness and Emotions in a Cross-Cultural Perspective. Spell: Swiss papers in English language and literature, Türbingen, v. 30, n. 1, p. 67-88, jan. 2014.

CULPEPER, J.; HAUGH, M.; KÁDÁR, D. The Palgrave Handbook of Linguistic (Im)Politeness, [s.1.]: Palgrave Macmillan UK, 2017.

CULPEPER, J; HARDAKER, C. Impoliteness. In: CULPEPER, J; KÁDÁR, D; HAUGH, M (Ed.). The Palgrave Handbook of Impoliteness. [s.1.]: Palgrave, 2017, p. 199-226.

EELEN, G. A critique of politeness theory. Manchester: St. Jerome, 2001.

GUMPERZ, J. J. Discourse Strategies. Cambridge: Cambridge University, 1982.

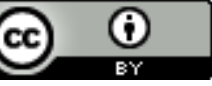

Este texto está licenciado com uma Licença Creative Commons Atribuição 4.0 Internacional.

BARRETO FILHO, Ricardo Rios; BARROS, Kazue Saito Monteiro de. Impolidez e identidades em uma interação on-line no Facebook: uma abordagem sociodiscursiva. Linguagem em (Dis)curso - LemD, Tubarão, SC, v. 21, n. 1, p. 135-149, jan./abr. 2021. 